\title{
Control of Non-Standard Dynamic Objects With the Method of Adaptation According to the Misalignment Based on Neural Networks
}

\author{
Nodirbek Yusupbekov ${ }^{1}{ }^{1}$ Tashkent State Technical University, Uzbekistan, dodabek@ mail.ru \\ Djalolitdin Mukhitdinov ${ }^{2}{ }^{2}$ Tashkent State Technical University, Uzbekistan, muxitdinov@mail.ru \\ Yorkin Kadirov ${ }^{3},{ }^{3}$ Navoi State Mining Institute, Uzbekistan, navdki@mail.ru \\ Olim Sattarov ${ }^{4}{ }^{4}$ Navoi State Mining Institute, Uzbekistan, olim81@bk.ru \\ Abdukhalil Samadov ${ }^{5},{ }^{5}$ Navoi State Mining Institute, Uzbekistan, samadov.abduxalil@mail.ru
}

\begin{abstract}
The article discusses the procedure for building a neural network control system for dynamic objects. The methods of continuous adaptation of a neural network controller with neural network adjustment to changes in the dynamic characteristics of an object and adaptation to a mismatch signal are compared. To eliminate the shortcomings of the first method, the control loop is supplemented with a block for detecting changes in the state of the control object, designed to detect the signal of mismatch with the "set point". In order to ensure the reliability of detection of the mismatch signal, paired response is taken into account within the calculated value of the average delay time. The neural network model of the control object is adjusted outside the control loop. To detect mismatch in a timely manner, an algorithm of cumulative sums is configured, in which the defining characteristics are the average delay time and the average time between false positives.
\end{abstract}

Key words : Control object, dynamic process, steady state, closed loop, stationary mode, neural network controller, neural network identifier, neural networks, optimal neuro controller, information collection algorithm, cumulative sum algorithm, sets, training sets, bimodal form, control loop, approximation, undefined function, mismatch, adaptation method.

\section{INTRODUCTION}

On the basis of the research carried out for the control of non-stationary objects, a new method of neural network control is proposed, adapting to establish the mismatch between the state of the object and the "set point". An approach is proposed for the rational collection of information for adapting the object after detecting the mismatch, based on the properties of the cumulative sum algorithm. Computational studies on an unevenly changing linear control object with the implementation of continuous adaptation and adaptation methods for detecting mismatch showed that the first method has a higher performance compared to the adaptation method for detecting mismatch, but less stability. Identification was carried out under stationary conditions with continuous adaptation and adaptation by detection of mismatch, and also the root-mean-square error of control was determined for various adaptation options, which showed that the control errors do not exceed the permissible limits (in this case, it is 0.55 ).

\section{METHODS AND MATERIALS}

The solution to the problem posed is quite difficult, for its solution the method of continuous adaptation of the neural network controller is often used when the neural network adjusts to changes in the dynamic characteristics of the object [1-4]. This method involves the use of a neural network, when connections between neurons do not form closed loops, and information propagates in only one direction from inputs to outputs. Using direct or indirect neural network inversion of the control object within the framework of the neural network control tuning algorithms, an adaptation method can be implemented.

The regulation of the neural network of a non-stationary object is carried out using a trained neural network acting as a control object. In contrast to stationary conditions when neural network identification can be carried out once, in dynamic conditions when the features of an object are not constant, both the neural network control and the neural network identifier must be adapted [5]. If the adaptation algorithm works incorrectly, all neural networks are constantly in the tuning mode. Below is a diagram of a control system with a continuous adaptation algorithm.

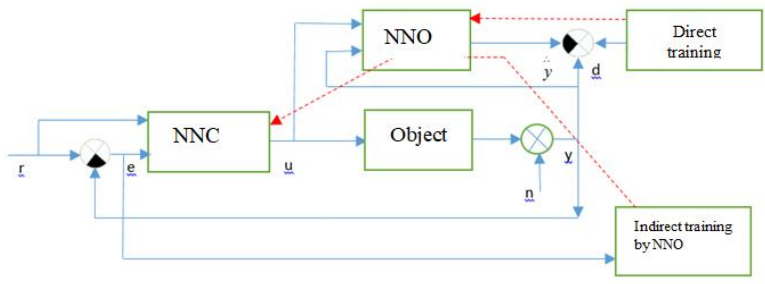

Figure. 1: Control loop with continuous adaptation scheme. 
External signals of the control system are the "set point" and additive interference of the object output under consideration. To minimize the control error, the controller generates a control effect $u$ on the CO. Based on the control effect and previous measurements of the object's outputs, the ID neural network enabled in parallel with the object predicts the [6] future behavior of the system. The scheme is supplemented with neural network adjustment algorithms: direct training of the neural network ID based on the ID error, and indirect training of the control neural network, when the propagation of the control error e occurs by the reverse method through the $\mathrm{NNO}$ to the NNC and the error between the actual and predicted [7] responses is minimized.

Figure 2. shows the architecture of the control's neural networks. In order to improve the quality of modeling the dynamic modes of the controlled object, signals $u$ and $y$ of the last few moments of time are sent to the inputs. (Fig. 2a). The value of the control error is fed to the input device of the neural network control, together with the "set point" (Fig. 2b), which predetermines the dynamics of regulation when feedbacks are unavailable in neural [8] networks.

In accordance with the above training scheme, the problem of minimizing the control error is assigned to the neural network of the control, whose coefficients are intentionally changed for these purposes. Therefore, corrections of weight coefficients are calculated independently and do not have a mutual effect. In this case, the preparation takes place in real time and without a control sample. Moreover, over a number of cycles of operation of the digital control system, there is a constant addition of variations in weight coefficients. The result is used with a certain frequency, as it happens in the batch method, which allows stabilizing the control loop (accidental incorrect changes in the NRS can lead to an incorrect change in the NDS). This makes it possible to get rid of irregular atomic changes in weight coefficients. Analysis of the constant adaptation method shows that it is not entirely economical due to the constant inclusion of the training algorithm for both neural networks. It should also be noted that the parameters of the object are undergoing rapid and significant changes. This often leads to the loss of the control system from stability. It follows from the above that this method is acceptable for cases with a gradual and slow [9] change in the parameters of the object.

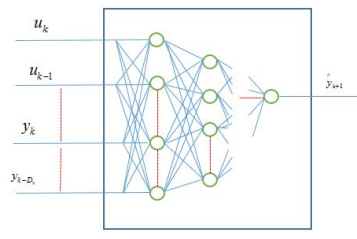

a)

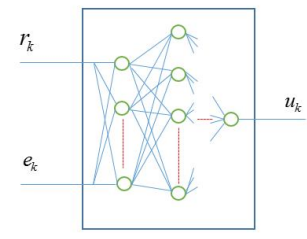

b)
Figure. 2: The architecture of neural networks

To eliminate the disadvantages of the above method, a block for detecting changes in the states of a controlled object (Fig. 3 ) was introduced into the circuit, which, upon detecting an error signal with the "set point", collects additional information in order to train the identifier neural network outside the control loop. Upon completion of the training of the identifier neural network, the block is included in the NNC adaptation scheme, which is in the active mode (Fig. 4), similar to the scheme for the synthesis of the optimal neuro-control in the stationary case.

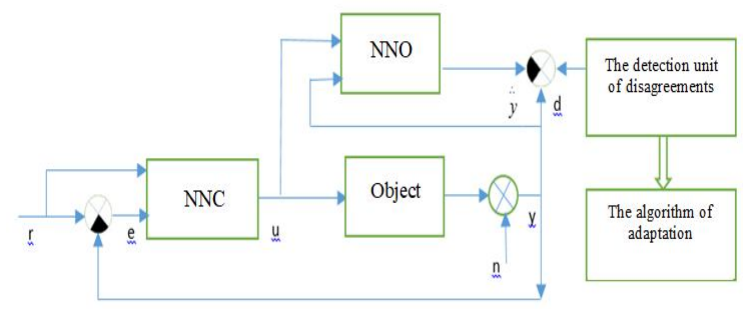

Figure: 3: Control loop in a stationary system. It should be emphasized that the presented scheme uses neural networks that correspond to the architecture in the method with continuous adaptation (Fig. 2).

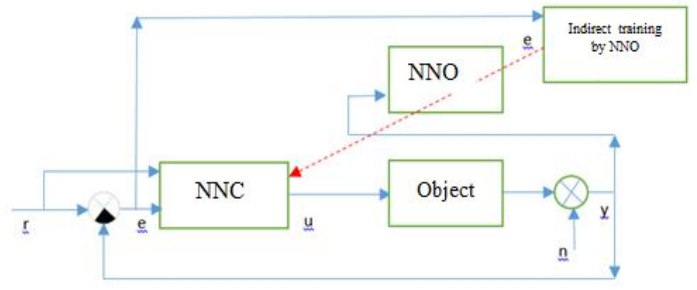

Figure. 4: The control scheme in the steady state. In order for the scheme to function reliably in non-stationary situations, it is necessary to determine the periods of changes in the object's characteristics as accurately as possible and adjust its model accordingly. The problem of detecting mismatch is solved using the cumulative sum algorithm. To ensure the reliability of detecting the mismatch signal, the pair response within the calculated value is taken into account $T_{a d}$. The neural network model of the control object must be adjusted outside the control loop. Qualitative prediction of the behavior of the control object and training of the neural network controller, produced on a sufficiently large amount of training data, provides training for the neural network. To automate the adaptation procedure, it is necessary to develop a reasonable algorithm for collecting information.

In order to timely detect the mismatch, it is necessary to appropriately adjust the cumulative sum algorithm, for which the main controllable parameter is the decision boundary (threshold). The main characteristics of the cumulative sums algorithm are the average delay time and the average time between false alarms, which affect the duration of losses resulting from the transformation $[10,11]$ of the parameters of the controlled object.

To configure the cumulative sum algorithm, it is imperative to enter the numerical value of the controlled parameter before the discrepancy, the predicted value of the same parameter in case of discrepancy, $H>0$ in addition, it is necessary to select a threshold that could provide the desired parameters $T_{a d}$ and $T_{f a}$.

The parameter that qualitatively determines the change in the values of the control object can be the variance of the 
recognition error $. d=y-\hat{y}$. At the same time, the variance calculated for the stationary state of the system $\sigma_{0}^{2}$ should be taken as the initial numerical value, and for the nominal discrepancy - its increase in a given number of times (for example $K=2$ ).

The magnitude of the mismatch can be calculated from the variance of a random process with a normal distribution. To do this, the terms of the equation displaying the distribution of points calculated by the cumulative sum algorithm must be calculated by the formula:

$$
z_{i}=-\frac{1}{2} \ln \frac{\sigma_{1}^{2}}{\sigma_{0}^{2}}-\frac{1}{2}\left(\frac{1}{\sigma_{1}^{2}}-\frac{1}{\sigma_{0}^{2}}\right) d_{i}^{2}
$$

In this case, the equation for performing an elementary verification procedure, which displays points in the classical algorithm of cumulative sums, is expressed by the ratio:

$$
S_{i}=\left\{\begin{array}{l}
0, \quad i=0 \\
\max \left(0 ; S_{i-1}+z_{i}\right), i>0
\end{array}\right.
$$

The mismatch criterion is the point $\mathrm{Si}$ reaching the decisive boundary $\mathrm{H}$.

When this condition is met, the mismatch is considered detected, the check procedure ends if there is no need to start the next one. With an increase in the threshold, the delay between the actual change in the parameters of the random process and the moment of occurrence of the mismatch increases, and its small value leads to an increase in the number of false alarms due to the randomness of the process.

Based on a certain compromise value between $T_{a d}$ and $T_{f a}$ the selection method $\mathrm{H}$, the cumulative sum algorithm is adjusted. To ensure the reliability of mismatch diagnostics, it is necessary to analyze its presence by means of a test run of the algorithm. A mismatch is considered confirmed if a signal about it appears in the interval up to $3 T_{a d}$, while the actual delay time is doubled.

In papers, a method is proposed for calculating the characteristics of the cumulative sums algorithm for uncorrelated random processes, based on the distribution parameters of a random process.

As a result of our experiments, some discrepancy between the measured and calculated characteristics of the algorithm was revealed. This deviation, in our opinion, lies in the fact that the inaccuracy of identification in the studied control system is random, and the technological process is correlated.

The studies carried out made it possible to determine the dependence of the characteristics $T_{a d}$ and $T_{f a}$ on the value of the threshold $\mathrm{H}$ and use them to correct the algorithm (Fig. $5,6)$.

As a result of changes in the characteristics of the object and the adjustment of neural networks, the variances of the identification error characterizing the new steady state can also change. In this case, correction of the algorithm parameters is required.

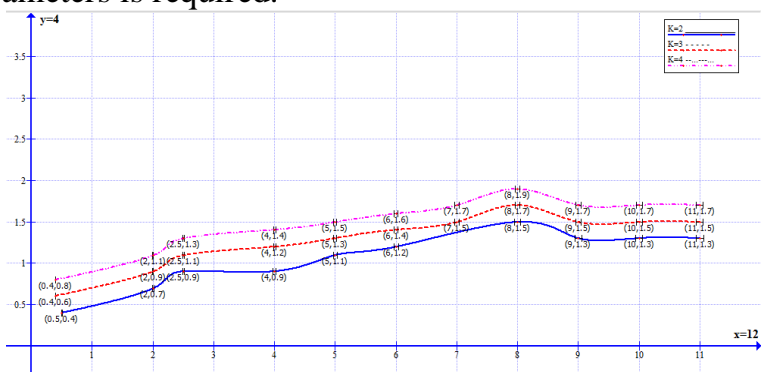

Figure: 5:. Dependence of the average delay time on the threshold $\mathrm{H}$ for various nominal disturbances $\mathrm{K}$.

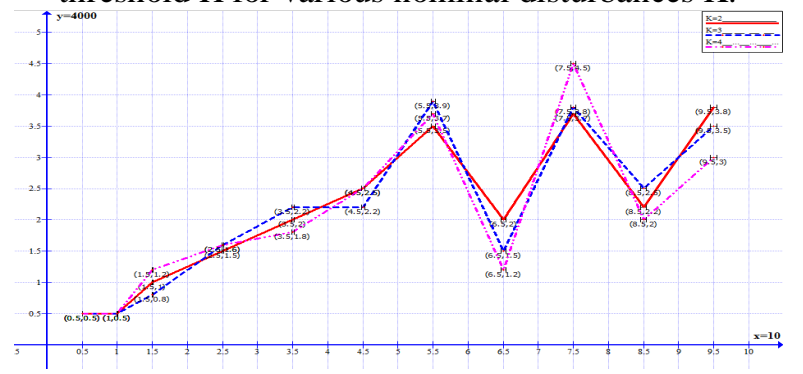

Figure: 6: Dependence of the average time between false positives on the threshold $\mathrm{H}$ for various nominal layouts $\mathrm{K}$. The formation of a training sample for adjusting the NNO when a mismatch is detected [12-13] depends on the size of the training sample $\mathrm{N}$ and the method of its formation.

The standard approach of using a training sample of a constant length is not suitable in this case, since the NNO adjustment must be followed regularly with the detection of an error signal. The appearance of a mismatch means that the system has gone out of optimal mode and must be optimized in the shortest possible time. The quality of NDS training depends on how the NSS is configured, and the quality of the NSS tuning, in turn, depends on the length of the training sample. With an increase in the length of the training sample, the control efficiency decreases, and in some cases this can lead to a loss of stability.

Taking this into account, the components $\left\{u_{k}\right\} \mathrm{N}$ and $\left\{y_{k}\right\}_{\mathrm{N}}$ were used in the work as the defining sample, representing the segment from the starting point of reference

$t_{0}$ of the last control procedure of the AKC to the moment of receiving a signal $t_{1}$ about the presence of a mismatch plus $\mathrm{M}$ similar values that appeared before the moment, since the AKS issues an error signal with a delay relative to the start time of the process $t_{0}$ characteristics change.

Since the time interval $t_{1}-t_{0}$ is a random value, the training sample will also be of a random length $N=2 M$, the size that can be taken as the minimum size of the training set. It can be used to configure the identifier neural network as soon as the mismatch signal is detected. With a very small length of the interval $t_{1}-t_{0}$, the size of this sample may not be sufficient for high-quality training of the NNO. In this case, it 
becomes necessary to estimate the parameter of the bivariate distribution $(u, y)$ from the previously obtained data and collect the values $u_{k}, y_{k}$ of the observed parameters before filling the selected area with the required density. From figure 7., where the two-dimensional density of the point $(u, y)$ spread is shown, it can be seen that it has a bimodal appearance. On the basis of the presented algorithm, it is possible to dynamically form a training set, which is used when setting up the NNO outside the control loop, to approximate an undefined function that can predict the behavior of the control object.

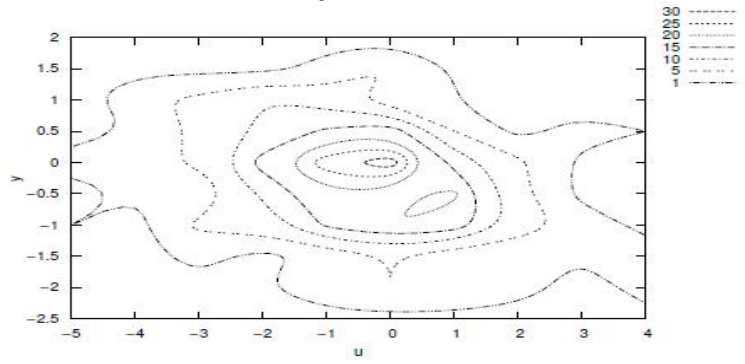

Figure: 7: Two-dimensional distribution $(\mathrm{u}, \mathrm{y})$ with contours of equal coverage density

In order to study the properties and obtain numerical estimates of the quality of neural network control for the case with constant adaptation and with adaptation by detecting the mismatch on a computer model, a number of computational experiments were carried out. To assess the quality, two criteria were chosen: the standard deviation of the control, showing information about integral errors and the values of the spread of the control error, showing the possible maximum values of errors fraught with the OA going beyond the limits allowed by the technological regulations. In experiments with a stationary object of regulation, the action of neural networks with control systems in means that do not require reconfiguration [14-17] was investigated. When using a neural control network with continuous adaptation (Fig. 8), there were significant fluctuations in the regulation feature with a torque of $2 \times 105 \ldots 5 \times 105$ sub reports and an amplitude from 0.05 to 6 .

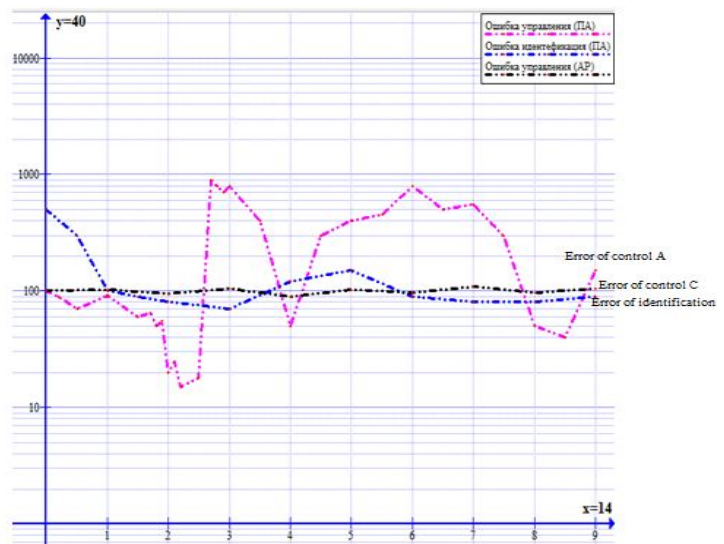

Figure 8: Root mean square error of regulation and identification in stationary conditions with continuous adaptation (PA) and adaptation for mismatch detection (AR).
Analyzing the graph, it can be noted that fluctuations in the mean-square inaccuracy of identification $d$ in the continuous adaptation system occurred in the opposite phase of the control inaccuracy, and the neuro-control provided minor fluctuations near the mean-square error of regulation 0.121. when studying the statistical distribution of the control error, it was found that the error was distributed according to a law approaching the Gaussian distribution (Fig.9).

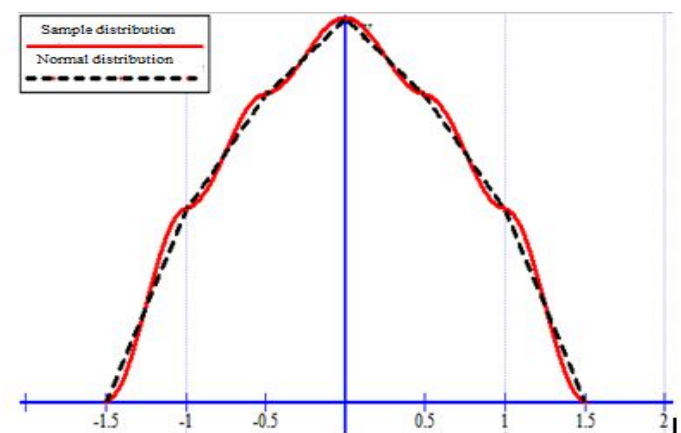

Figure 9: The spread of the control error during adaptation to determine the mismatch in stationary states.

The conducted research has confirmed that the statistical distribution of the error in the modes of continuous adaptation does not mean that it is constant, and with a decrease in the quality of regulation, its mean values strongly differ from zero. In fig. 4.10 shows the graphs of the spread of the control error in two time intervals and for a full sample. Analysis of the figure allows us to conclude that in the area of the period of better regulation quality $[0.4 \times 105]$ (Fig. 8), the distribution of points occurs according to the normal law, and in periods of the worst quality of regulation $[4 \times 105.8 \times 105]$ - distribution is multimodal.

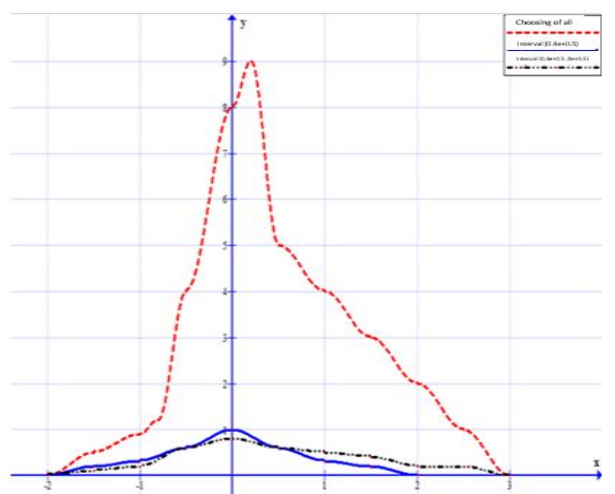

Figure 10: The spread of the control error with continuous adaptation in a steady state.

Table 1 shows the probabilistic parameters of the control error spread

Table 1:Probabilistic parameters of the control error spread

\begin{tabular}{|l|l|l|l|l|}
\hline & $\begin{array}{l}\text { Mini } \\
\text { mum }\end{array}$ & $\begin{array}{l}\text { Maxi } \\
\text { mum }\end{array}$ & $\begin{array}{l}\text { Avera } \\
\text { ge }\end{array}$ & $\begin{array}{l}\text { Dispersio } \\
\text { n }\end{array}$ \\
\hline $\begin{array}{l}\text { Continuous } \\
\text { adaptation }\end{array}$ & -2.03 & 5.43 & 0.33 & 0.30 \\
\hline $\begin{array}{l}\text { Misalignment } \\
\text { adaptation }\end{array}$ & -1.46 & 1.52 & -0.01 & 0.12 \\
\hline
\end{tabular}


The research carried out with non-stationary control lenses showed that in the period of time 500 its values changed abruptly. Figure 11 shows the root-mean-square errors under three different circumstances: no adaptation of the neural network control, continuous adaptation of values after mismatch diagnostics, and learning the NNO outside the system. Time transformations of the object characteristics and the beginning of adaptation of the neural network control in combination with mismatch adaptation are marked with vertical lines.

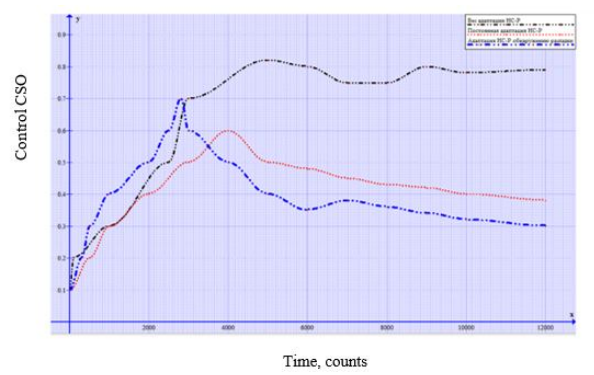

Figure. 11: Root mean square error of control with different adaptation options.

It follows from the analysis of the figure that the neurocontrol with continuous adaptation responds to changes in the object rather quickly and does not allow the regulation error to grow more than 0.55 . Nevertheless, after a while, the control error begins to grow. To apply the adaptation method based on the determination of the mismatch, the collection of information is required for reconfiguring the neural network controller. In our experiment with a volume of 600 samples for training, the root mean square error of control increased to 0.6. Then, conditionally, we can say that the reconfiguration of the neural network identifier occurs instantly and at the 1100 mark, the adaptation of the neural network control begins. During this period, the error increased to 0.7 , which is similar to the indicator of a neural network control without adaptation. After that, the control error began to decrease at a faster rate than when using the continuous adaptation method. The distribution parameters of the control error in the adaptation process under non-stationary conditions are given in Table 2.

Table 2: Parameters of control error distribution in non-stationary conditions.

\begin{tabular}{|l|l|l|l|l|}
\hline & $\begin{array}{l}\text { Mini } \\
\text { mum }\end{array}$ & $\begin{array}{l}\text { Maxim } \\
\text { um }\end{array}$ & $\begin{array}{l}\text { Avera } \\
\text { ge }\end{array}$ & $\begin{array}{l}\text { Dispersi } \\
\text { on }\end{array}$ \\
\hline $\begin{array}{l}\text { Continuous } \\
\text { adaptation }\end{array}$ & $\begin{array}{l}-12.3 \\
1\end{array}$ & 3.62 & -5.23 & 10.51 \\
\hline $\begin{array}{l}\text { Misalignme } \\
\text { nt } \\
\text { adaptation }\end{array}$ & -1.98 & 2.00 & -0.01 & 0.46 \\
\hline
\end{tabular}

\section{CONCLUSION}

On the basis of the research carried out for the control of non-standard objects, a new method of neural network control is proposed, adapting to establish the mismatch between the state of the object and the "setting". An approach is proposed for the rational collection of information for adapting an object after detecting the mismatch, based on the properties of the cumulative sum algorithm. Computational studies were carried out on a non-uniformly varying linear control plant with the implementation of continuous adaptation and adaptation methods for detecting mismatch showed that the first method has a faster response compared to the adaptation method for detecting mismatch, but less stability.

\section{REFERENCES}

1. S. Chen, B. Mulgrew, and P. M. Grant. A clustering technique for digital communications channel equalization using radial basis function networks, IEEE Trans. on Neural Networks, Vol. 4, pp. 570-578, July 1993.

2. J. U. Duncombe. Infrared navigation-Part I: An assessment of feasibility, IEEE Trans. Electron Devices, vol. ED-11, pp. 34-39, Jan. 1959.

3. C. Y. Lin, M. Wu, J. A. Bloom, I. J. Cox, and M. Miller. Rotation, scale, and translation resilient public watermarking for images, IEEE Trans. Image Process., vol. 10, no. 5, pp. 767-782, May 2001.

4. A. Cichocki and R. Unbehaven. Neural Networks for Optimization and Signal Processing, 1st ed. Chichester, U.K.: Wiley, 1993, ch. 2, pp. 45-47.

5. W.-K. Chen. Linear Networks and Systems, Belmont, CA: Wadsworth, 1993, pp. 123-135.

6. H. Poor. An Introduction to Signal Detection and Estimation; New York: Springer-Verlag, 1985, ch. 4.

7. R. A. Scholtz. The Spread Spectrum Concept, in Multiple Access, N. Abramson, Ed. Piscataway, NJ: IEEE Press, 1993, ch. 3, pp. 121-123.

8. G. O. Young. Synthetic structure of industrial plastics, in Plastics, 2nd ed. vol. 3, J. Peters, Ed. New York: McGraw-Hill, 1964, pp. 15-64.

9. S. P. Bingulac. On the compatibility of adaptive controllers, in Proc. 4th Annu. Allerton Conf. Circuits and Systems Theory, New York, 1994, pp. 8-16.

10. W. D. Doyle. Magnetization reversal in films with biaxial anisotropy, in Proc. 1987 INTERMAG Conf., 1987, pp. 2.2-1-2.2-6.

11. J. Williams. Narrow-band analyzer, Ph.D. dissertation, Dept. Elect. Eng., Harvard Univ., Cambridge, MA, 1993.

12. N. Kawasaki. Parametric study of thermal and chemical nonequilibrium nozzle flow, M.S. thesis, Dept. Electron. Eng., Osaka Univ., Osaka, Japan, 1993.

13.

14. I.G.Svenger, I.R.Nizamov. Primenenie neyrosetevix regulyatorov $v$ sistemax upravleniya elektroprivodami. Vestnik texnologicheskogo universiteta, Tashkent 2017. T20 №8, pp 342-345.

15. Kabirova Aygul Nadilevna. Metodi i kompleksi programm postroeniya neyrosetevix modeley regulyatorov dlya upravleniya dinamicheskim 
ob'ektom. Ph.D. dissertation, Kazan univ., Russia, 2017.

16. V.A.Terexov, I.YU.Tyukin. Sintez adaptivnix neyrosetevix regulyatorax nelineynix dinamicheskix ob'ektov. Institute for Physical and Chemical Research (RIKEN), Japan 2017.

17. D.P. Muxitdinov, Yo.B. Kadirov, O.U. Sattarov. Razrabotka mnogosvyaznoy dinamicheskoy modeli protsessa ekstraksii fosfornoy kisloti $\mathrm{v}$ digidratnom rejime. Kompozitsionnie materiali. Nauchno-texnicheskiy i proizvodstvenniy jurnal, 2019 № 2, pp 132-135.

18. E.V.Leonidovich. Razrabotka i issledovanie neyrosetevix algoritmov upravleniya statsionarnimi i nestatsionarnimi ob'ektami, . Ph.D. dissertation, Moscow national univ., Russia, 2012.

19. Babinkov V.A. Povishenie effektivnosti upravleniya texnologicheskimi protsessami $s$ ispolzovaniem nablyudateley i regulyatorov sostoyaniya (a primere proizvodstva ekstraksionoy fosfornoy kisloti), Ph.D. dissertation, Starie -Oskol univ., Russia, 2015.

20. Filaretov G. F., Eliseev V. L., Modified Algorithm of Neural Network Control for Non-stationary Object $55 h$ International Scientific Colloquium. Ilmenau University of Technology: 2010,pp 125-130.

21. Yusupbekov N.R., Muxitdinov D.P., Sattarov O.U., Boybutaev S.B. Construction of a Neural Network Using an Approach to a Genetic Algorithm. International Journal of Advanced Research in Science, Engineering and Technology Vol. 6, Issue 6, June 2019., India .

22. Saprikina N.A. Parametricheskie podxodi formirovaniya arxitekturnoy sredi $\mathrm{v}$ kontekste adaptatsii i interaktivnosti. Nauka, obrazovanie $i$ eksperimentalnoe proektirovanie. Materiali mejdunarodnoy nauchno-prakticheskoy konferensii. Sbornik statey. $2016 \quad$ Izdatelstvo: Moskovskiy arxitekturniy institut (gosudarstvennaya akademiya), Moskow 2016 pp 408-412.

23. Muxitdinov D.P., Kadirov Yo.B., Sattarov O.U., Boybutaev S.B. Proporsionalno - integralnodifferensiruyushie regulyatori $v$ avtomatizirovannix sistemax upravleniya texnologicheskim protsessom. Nauchno - texnicheskiy $i$ proizvodstvenniy jurnal «Gorniy vestnik Uzbekistana» №4. , Navoi 2014.

24. A.G. Goryunov, Yu.A. Chursin, S.S. Mixalevich, D.G. Rogozniy. Dinamecheskaya model mnogokomponentnogo neravnovesnogo ekstraksionnogo protsessa $\mathbf{v}$ kolonnom ekstraktore. Izvestiya visshix uchebnix zavedeniy. Fizika, 2010.-№1182. Russia - pp.210-214.

25. Rikov V.P. Modulniy prinsip obucheniya iskusstvennix neyronnix setey na primere izvestnix neyrosetevix topologiy. Vestnik TGU, t. 19, vip. 2, 2014. -Uzbekistan pp. 583-586.
26. Beale M., Hagan M., Demuth H. Neural Network Toolbox TM User's Guide. The Math Works, Inc, 2015. pp - 406

27. Sattarov O.U. Issledovanie protsessa polucheniya azotno-fosfornix udobreniy na osnove plava ammiachnoy selitri i fosforitov. Nauchno - texnicheskiy $i$ proizvodstvenniy jurnal «Sovremennie materiali, texnika i texnologii» 16-17, February 2017 year, №8 pp164-170.

28. A.G.SHumixin, A.S. Boyarshinova. Primenenie neyrosetevix dinamicheskix modeley $v$ zadache parametricheskoy identifikatsii texnologicheskogo ob'ekta v sostave sistemi upravleniya. Vestnik PNIPU, Perm 2015 g, Russia, pp 21-36

29. Aaron Don M. Africa, Gerard Ching, Kerwin Go, Rency Evidente, Jason Uy. A Comprehensive Study on Application Development Software Systems International Journal of Emerging Trends in Engineering Research, Volume 7, No.8, India, August 2019

30. Aaron Don M. Africa, Isaiah Kyle A. Naco, John Joseph M. Castillo, Victor Antonio R. Valdes, Shawn Reece T. Wu. ANN Distance Protection for Transmission Lines, International Journal of Emerging Trends in Engineering Research, Volume 7, No.8 India, August 2019 